\title{
Research on the innovation of human resources management of university teachers from the perspective of core competitiveness
}

\author{
Lili Lu \\ Xi'an International University, Human Resource Management, Xi'an Shaanxi, China, 710077
}

Keywords: core competitiveness, university human resources, management innovation.

Abstract: economic globalization and internationalization of education have made higher education competition increasingly fierce in China. Developing the core competitiveness of the organization has become an inevitable choice for the survival and development of colleges and universities. Core competition of universities is the accumulation system formed by the unique knowledge of the school, and its deep connotation includes excellent culture and advanced system are concentrated on the ability of talents and academic research. And the ability to serve the society, all of them are based on the high level of human resources. At present, the problems in the development and management of human resources in Chinese universities are quite serious. In order to improve the quality of education and the efficiency of running schools, it is necessary to improve the quality and efficiency of running colleges and universities. The overall quality of human resources in universities depends largely on human resources which only adhere to the "people-oriented" concept of human resources development through human resources. The management system and operation mechanism should be innovating, and a reasonable and effective plan for human resource development and management should be worked out. In order to meet the requirements of scientific whose standardized and democratized human resources development and management in universities and colleges. Finally, It is significant to cultivate and enhance the core competitiveness of the school.

\section{With the rapid development of economic globalization and education internationalization, and the popularization of higher education in China has expanded widely}

The process of promoting has raply expanded among the scale of running schools, the differentiation and reorganization among universities, and the private higher education.

In the field of economic, universities must first acquire competitive advantages in order to become the winner of market competition. Therefore, upgrading the core competitiveness has become a strategic choice for the development of colleges and universities. Human resources are colleges and universities. The first resource is the most important and direct force to create university value and form university dominance. In a sense, the disparity of the comprehensive strength of a school is expressed as the difference between the quality and quantity of human resources. Universities must implement human resources management which conforms to the 
organizational characteristics of universities and adapts to the requirements of social development. Rational innovation fosters its core competitiveness, integrated with quicker technological innovation and faster knowledge. It refers to accumulated knowledge in enterprise organization, especially on how to coordinate different production skills. And integrate all kinds of technology knowledge and get the unique ability to surpass other competitors.

1) After the 90s of the 20th century, core competitiveness became a popular topic in western economics. These studies further enrich and develop the core competitiveness theory. Despite the expert's statement on different points from each other, but the basic connotation is the formation of enterprises in the long run process. And unique ability to bring extra profits and sustained gains the competitive advantage.

2) Although the theory of core competitiveness is proposed for economic laws, without belonging exclusively to enterprises. It is the ability of all organizations in a competitive environment to achieve their own development. The concept of contention has a profound inspiration and reference value in the field of higher education. The core competitiveness is based on scientific strategic decisions, through internal management system and operation. The reform and innovation of the mechanism should be carried out in order to condense high-level teachers and carry out scientific research at a high level. The competitiveness of the heart is a special way for universities to maintain effective vitality which lasts survival and development in fierce competition. Advantage is one of most important key factors to maintain and enhance the competitive advantage. The core competitiveness of learning is the accumulation system which is formed by the unique knowledge of a school includes deep culture and excellent culture. Whether the operation mechanism of human resource management is effective or not?

3) Human resources in colleges and universities are the most direct driving force for the development of colleges and universities, and also the development of resources in colleges and universities. It is strong power of core competitiveness and the object of competition among universities for sesting up a branch and a team of fairly large scale is relatively stable which is dedicated and solid knowledge. The team is the intellectual prerequisite for cultivating and enhancing the core competitiveness of universities, through the development of scientific education and technology development strategy is the biggest innovation by school culture, management system and operation mechanism. It is the school that develops the intelligence resources of all personnel and mobilizes their initiative and creativity. The core of human resources work is the inevitable choice to cultivate and enhance the core competitiveness of colleges and universities.

\section{Analysis of the current situation of human resources management in Chinese Universities}

The problems that exists in the development and management of human resources in Colleges and universities in are still very sudden and seriously affected. It is more common that quality of education and the improvement of school running efficiency. The degree is different. The concept of human resources development and management is relatively lagging behind. The human resource management in China universities is based on the traditional planned economy, which understanding of human resources management, is not in place for China. The management of force resources has not completely divorced from the idea of planned economy. It is understandable that the development of colleges and universities depends on input, whose the shortage of funds is the

bottleneck of the development of colleges and universities. Conscious of the real bottleneck is the lack of a high-quality faculty.

\subsection{The system of human resources development and management is not standardized}

Quite a number of colleges and universities has not yet established a scientific and reasonable 
system of human resources management which for means of force resource management can not fully meet the requirements of the new situation. Lack of effective long-term planning, compilation management, institutional setup and post setting are the problems. There are not enough human resources allocation, such as overstaffing, overstaffing and low efficiency. Forming the overall advantage of discipline is mainly compliance. Regardless of actual needs, they are highly arbitrary, leading to serious loss of human resources. The situation of unreasonable personnel structure and serious waste of talents, which is lack of standardized human resources training and stablethe system of incentives, is not yet complete.

\subsection{The mechanism of human resources development and management is not proper}

To a large extent, the management of "human head" in colleges and universities is still called "human head" management. To some extent, the phenomenon of "big pot" has dampened the enthusiasm of teaching staff. Human capital is still no effective mechanism for the allocation of resources. The free mobility of talents is relatively low which is difficult for all kinds of talents to achieve. Effective and effective allocation and rational use result in the phenomenon that talent can not stay and some talents are wasted. It seriously hinders the development of universities and the development of competitive advantages.

\section{To enhance the core competitiveness of colleges and universities human resources tourism}

The improvement of the overall quality of human resources in universities depends largely on the management of human resources.

\subsection{To establish a people-oriented concept of flexible management}

"People-oriented" is the essence and core of Scientific Outlook on Development, and is the emphasis on economic construction and social development. The guiding ideology is also an important guiding principle for human resources management in Colleges and universities, as far as theory is concerned. The management of human resources is emphasized on the basis of human nature, which requires full exploitation of human potential and human centered. Pay attention to the coordinated development of people and organizations; in terms of organizational characteristics, colleges and universities take knowledge work as the main body. The typical "knowledge intensive" and "intelligence intensive" people organization, teachers are the first life of a school whose elements of production and core strategic resources survive and possess a high quality and high quality. The faculty in university is the most educated social group with the highest human nature basis. It is suitable for carrying out humanistic management philosophy. To carry out the innovation of human resources management in colleges and universities. It is the transformation of ideas that universities should set up teachers' standards in the light of the characteristics of knowledge work and university teachers. The functions and mechanisms of the department should establish a modern center which is related toteachers whose management mode with teachers as the center. The requirements of human resources management in colleges and universities. Meanwhile, the flow of teachers, global allocation of resources set up the ever-changing external environment such as running schools requires flexibility and organization of management system.

\subsection{To establish a talent development mechanism for internal training}

At present, many university faculty members still have irrational learning structure and knowledge. 
The problem that the production efficiency is not high, leading to the teaching masters and academic masters which are short, and so on. The strength is not strong. This requires top-notch innovation, talent training, selection and introduction mechanism reform. But through the improvement of key positions and key posts, the graduates can get better treatment. Foreign talents provide broad development space and create a good working environment.

Those excellent young and middle-aged teachers who have potential and grow into academic leaders outside school. In the process of talent introduction, we should deal well with the relationship between education and ability, academic and moral. The two aspects must be balanced. Performance evaluation of teachers' teaching and scientific research will be conducted. The results are closely integrated with distribution, promotion and renewal, and lack of responsibility and development potential. The teachers from the relevant positions are cleaned up by education, training, transfer and dismissal.

\subsection{To establish a scientific and impartial performance appraisal mechanism}

"It doesn't make much sense to evaluate companies by university standards and to evaluate the economy by the standards of the higher education system.

The system will not be of great significance. Similarly, it is not advisable to evaluate the higher education system by evaluating the criteria of the economic system. Therefore, according to the requirements of different disciplines and different levels of posts, we must establish a scientific university organization and academic management. According to the subject characteristics, aptitude and research interests of different teachers, and in accordance with the requirements of organizational goals, different standards should be implemented. Appraisal methods should not be all-inclusive. Apart from giving full play to the positive role of students in teaching quality evaluation, teachers should be appointed, promoted and appointed. Peer evaluation, especially off-campus peer evaluation, should play a very important role in the decision of term and the application of scientific research funds. Then the performance and post-related treatment and performance corresponding, so that talent selection, promotion and research funding is based on the acquisition of individual talent. On the basis of ability, we can bring up a kind of backward, pressure, dynamic and dynamic situation, stabilize and bring into playing the real talent.

The great role of talents ensures the good operation of university system and the formation of competitive advantages.

\subsection{To establish a fair and reasonable incentive mechanism}

The encouragement of talents is an important part of human resources development and management, and a guarantee for the success of school education. Harvard University studies the research, Professor William James found that in a lack of incentive environment, human potential is only $20 \%-309 \%$. The same people in the incentive environment can achieve a potential of 8 per thousand $90 \%, 8$. A fair and reasonable incentive mechanism is conducive to encouraging teaching. Teachers can get more returns by improving their professional ability and comprehensive quality, which is conducive to creating more contributions and ratios within the school. A good atmosphere of level and ability enables teachers to improve their own value while making more contributions. Internal motivation in the construction of schools. At the same time, The income distribution in Colleges and universities has been at a low level of egalitarianism for a long time. The low level makes the university teachers have a serious sense of external unfairness which induces the loss, equalitarianism makes them produce strict. Heavy internal sense of injustice, morale reduction and further increase of wastage rate, teachers' enthusiasm for long-term downturn is national income. The reform of the distribution system is an opportunity to further improve the school distribution 
system, to establish a high-level talents and key posts with emphasis on achievements and contributions. The allocation mechanism of bit tilt. Secondly, we should use mental motivation flexibly to stimulate teachers' inner drive. University teachers have their own unique characteristics. The need for values is largely at the level of Maslow's "respect for needs and self-fulfillment of needs" in which economic interests are taken into account. At the same time, it is more inclined to achieve their own career and realize their own value. Incentives should not be understood only as money but should be broader. Considering the needs of teachers at different levels, we should actively explore the ways to realize the distribution of knowledge elements according to their contributions. To adopt diversified forms of distribution to meet different levels of needs. For example, stronger research funding supports better working conditions. And so on, it causes the teacher to build up the relief school to grow together with me the relief spirit, producing the stronger intrinsic power, actively participates in the school education matter.

\section{Conclusively}

In order to implement human resource management in colleges and universities, we must establish the concept of "people-oriented" and a scientific human resource management system. The effective operation mechanism realizes the change from "event-oriented" to "people-oriented" realizes the change of management system from rigidity to the change of management culture from rationality to humanity creates a good environment for emotional cause to retain and attract people. Making good use of the advantages of human resources should promote the comprehensive efficiency of the university management system and foster and enhance the core competitiveness of the University.

\section{References}

[1] Qu Heng Chang the core competitiveness of advanced technology universities promotes the international competition of higher education in China [J].Competitive advantage "Comparative Education Research", second issue in 2005.

[2] Ma Shibin: the promotion of the core competitiveness of colleges and universities in the Warring States period [J], "learning sea", 2016.5

[3] Paul, editor in chief of S S Mayes, "knowledge management and organization" (JZhuhai publishing house, 98 edition, eighty-fourth pages.2018.3

[4] Zhu Jingkun and Yao Yixin: the construction of a scientific academic management system and operational mechanism in Universities2015.6

[5] Analysis, "Journal of Xuzhou Normal University" [J].(PHILOSOPHY AND SOCIAL SCIENCES EDITION, 2006 third issue).

[6] Shao Shouxian, Shan Ming Feng: "strategic human resource management in higher education institutions" $[J] .2016 .3$

[7] Burton R Clark: transnational organization of academic institutions of Higher Education Research, Hangzhou University Press[M]., 194 edition, 312nd pages.

[8] Liu Yan: analysis of the current situation and characteristics of University Teachers' human resources, [J]. Huaihua University Newspaper, 2017 tenth issue.

[9] Ma Shi Bin: the promotion of the core competitiveness of universities in the Warring States period, [J]. "learning sea", 2015.6

[10] Li Yu's Analysis and reform of Jsalary management in Colleges and Universitie[J] Journal of Liaoning Institute of administration 083 